\title{
Aborto numa lgreja mestra e mãe: na perspectiva de agentes de pastoral
}

\author{
Abortion in a master and mother Church: \\ from an agent of pastoral perspective
}

\author{
Mário Antônio Sanches \\ Castorina H. V. Casagrande \\ Eva Maria Duarte Gomes
}

\section{Resumo}

Introdução: Este artigo explicita a posição da Igreja Católica sobre o aborto em sua dupla perspectiva de Igreja Mestra e Mãe e busca explicitar a percepção de agentes de pastoral sobre estas duas perspectivas eclesiais. Método: Após revisão dos documentos da Igreja se desenvolve pesquisa de campo com agentes da pastoral da criança e da pastoral familiar, com o total de 316 entrevistados. Resultados: $\mathrm{O}$ artigo analisa o resultado de três questões: a) a posição sobre a legalização do aborto - identifica-se uma sintonia entre o ensinamento da Igreja e a percepção dos agentes, com situações também de desencontros; b) a postura dos agentes frente às pessoas que praticaram o aborto - percebe-se uma ampla postura de acolhida à pessoa que praticou o aborto, mas se identifica problema na ação das pastorais envolvidas; c) a responsabilidade sobre o aborto - nota-se que os agentes de pastoral assumem também uma consciência de uma responsabilidade compartilhada entre a mulher, a família e a sociedade sobre o aborto, quase excluindo o homem desta responsabilidade. Conclusão: embora haja muitos pontos de encontros entre o ensinamento da Igreja e a percepção dos agentes sobre o aborto, mas há também dissonâncias relevantes.

Palavras-chave: Aborto, Igreja, Pastoral, Bioética. 


\begin{abstract}
Introduction: this article explains the Catholic Church's position on abortion in its double perspective of a Church Master and Mother and seeks to clarify the perception of pastoral agents on these two ecclesial perspectives. Method: After reviewing the documents of the Church field research is developed with agents from children pastoral and family pastoral, with a total of 316 respondents. Results: the article analyses the outcome of three issues: a) the position on the legalization of abortion - identifies a harmony between the teaching of the Church and the perception of agents, with situations also mismatches; $b$ ) the attitude of the agents to persons who practiced abortion - it shows a wide position of welcoming to the person who performed the abortion, but identifies problem in the action of these pastorals involved; c) responsibility on abortion - note that the pastoral agents assume also an awareness of a shared responsibility between the woman, her family and society about abortion, almost excluding the man in this responsibility. Conclusion: Although there are many points of encounters between the teaching of the Church and the perception of the agents on abortion, but there are also relevant dissonances.
\end{abstract}

Keywords: Abortion, Church, Pastoral, Bioethics.

\title{
Introdução
}

Publicamos recentemente um artigo que abordou a temática do aborto numa perspectiva pastora ${ }^{1}$ onde apontamos para a necessidade de explicitarmos adequadamente a posição da Igreja como Mestra e Mãe sobre o assunto. $\mathrm{O}$ presente artigo se situa na continuidade deste trabalho e busca trazer dados de pesquisa de campo a respeito do modo como determinados setores de pastoral compreendem e refletem esta dupla perspectiva da Igreja. Por isso vamos retomar brevemente a reflexão sobre o assunto e ao mesmo tempo analisar os dados da pesquisa de campo realizada em Curitiba, Paraná.

É necessário explicitar que quando se trata do aborto numa perspectiva ética refere-se, evidentemente, ao aborto provocado. O aborto espontâneo, que ocorre por inúmeras causas, não implica em questões éticas, por mais

${ }^{1}$ SANCHES, M.A. O Aborto numa Perspectiva Pastoral. REB - Revista Eclesiástica Brasileira, Fasc. 285, Janeiro, 2012, p.119s. 
doloroso que possa ser para as pessoas envolvidas. Pastoralmente é bom recordar a diferença entre mal moral e mal natural. Somente o aborto provocado apresenta questões éticas, pois implica em análise da liberdade para praticar $\mathrm{o}$ ato e consciência do ato a ser praticado. O mal natural nós sofremos como condição de pertença ao mundo dos seres vivos, não o escolhemos.

O Documento de Aparecida exorta as pastorais da Igreja a se inserirem no "contexto histórico onde vivem seus membros", pois, de acordo com o documento as transformações sociais e culturais representam, "novos desafios para a Igreja em sua missão de construir o Reino de Deus”. (DAp, 367) Para que isto ocorra compreendemos que é necessário também revelar a realidade, desvendar as percepções que estão presentes em nossas comunidades e é isto que a pesquisa possibilita.

Deste modo, tentando nos aproximar de contextos específicos e promover uma cultura da vida queremos propor e argumentar que uma visão mais completa da posição da Igreja sobre o aborto é possível se a fizermos nesta dupla perspectiva: a posição da Igreja Mestra e a posição da Igreja Mãe. Entendemos que a falta de uma visão conjunta destas posições se dá porque o aborto não tem sido pensado numa dimensão pastoral, ou seja, isto reflete a dificuldade de percebermos que quando discutimos o aborto estamos avaliando duas coisas: o ato em si e a pessoa que o praticou. Estas realidades são diferentes: uma coisa é avaliar a moralidade do ato do aborto, outra coisa é pensar qual a melhor postura pastoral frente à pessoa que praticou o ato e que está inserida em condições sociais, históricas e pessoais bem determinadas.

\section{Método da pesquisa}

Neste artigo vamos apresentar os resultados de uma pesquisa que estudou a "problemática do aborto na Pastoral Familiar e Pastoral da Criança em Curitiba" e visa explicitar o que pensam os agentes destas pastorais sobre o tema. As pessoas selecionadas para participar desta pesquisa são agentes destas duas pastorais. Escolhemos estas pastorais por entender que estão vinculadas à questão da família e defesa da vida, ou seja, estão diretamente relacionadas com a problemática do aborto. Cremos que estas pastorais dispensam apresentações por causa de sua presença e atuação no cenário social e eclesial brasileiro.

A pesquisa foi previamente autorizada pelas coordenações dos grupos onde os questionários foram aplicados, bem como houve esclarecimento sobre o caráter sigiloso da mesma aos 316 participantes, em seguida eles assinaram 
o termo de consentimento livre e esclarecido, como recomenda a ética em pesquisa no Brasil. ${ }^{2} \mathrm{O}$ material utilizado na pesquisa constou de questionário estruturado, com dezoito questões. Foram excluídas da pesquisa as mulheres grávidas, pois se considerou não ser aconselhável tratar do tema do aborto com gestantes. Neste artigo vamos analisar apenas três das dezoito questões e cruzar os dados com o perfil dos entrevistados.

O questionário apresentou cinco variáveis de identificação das pessoas pesquisadas $^{3}$ : gênero, estado civil, faixa etária, escolaridade e tempo de participação nas pastorais. A maioria dos participantes da pesquisa $(63,9 \%)$ se identificaram como pertencentes ao sexo feminino. Portanto, a pesquisa confirma o que o Documento de Aparecida (455) já havia constatado que existe uma maior participação das mulheres nas pastorais, mas o engajamento masculino vem aumentando. Isso significa que conforme o mesmo documento aconselha, está havendo uma ativa participação dos homens, porque a Igreja passou a "promover espaço e serviço" (DAp, 463) para eles dentro das comunidades.

Quanto ao estado civil dos entrevistados apresentamos o quadro n.1, visto que este perfil deve ser levado em conta nos resultados que serão analisados de modo cruzado com outros dados da pesquisa.

\begin{tabular}{|l|c|c|}
\hline Estado civil & Frequência & Percentagem \\
\hline Solteiro & 52 & 16,5 \\
\hline Casado & 202 & 63,9 \\
\hline Viúvo & 18 & 5,7 \\
\hline União Estável & 18 & 5,7 \\
\hline Divorciado & 13 & 4,1 \\
\hline Não respondeu & 13 & 4,1 \\
\hline Total & 316 & 100,0 \\
\hline
\end{tabular}

Quadro n.1: Estado civil dos entrevistados. Fonte: os autores, 2014.

\footnotetext{
${ }^{2}$ Projeto submetido e aprovado pelo Comitê de Ética em Pesquisa da PUCPR, protocolo do CEP n. 5590, em setembro de 2011, seguindo as normas éticas sobre pesquisa com seres humanos (CNS, Resolução 196/97). A pesquisa de campo fora realizada em 2012, os questionários foram preenchidos pelos participantes da pesquisa quando estavam participando de algum encontro ou atividade relacionada com a pastoral em questão.

${ }^{3}$ A escolha dos participantes da pesquisa foi aleatória, de modo que a diferença de percentagem em relação a gênero, idade e outras variáveis, apenas revela o perfil dos grupos entrevistados.
} 
Quanto à idade a maioria dos participantes (46\%) era composta de pessoas entre trinta e um e cinquenta anos e praticamente $26 \%$ acima de 50 anos e os outros $26 \%$ entre 18 e 30 anos. O quadro n. 2 indica a escolaridade dos participantes da pesquisa. O grau de instrução dos participantes, com mais de $60 \%$ tendo concluído ensino médio, precisa ser considerado na análise dos resultados, pois possivelmente teríamos resultados diversos se a pesquisa fosse realizada com pessoas com menor escolaridade.

\begin{tabular}{|l|l|l|}
\hline Escolaridade & Frequência & Percentagem \\
\hline Não concluiu a 4 série & 24 & 7,6 \\
\hline Concluiu a 4 série & 41 & 13,0 \\
\hline Concluiu o ensino fundamental & 47 & 14,9 \\
\hline Concluiu o ensino médio & 112 & 35,4 \\
\hline Concluiu o curso superior & 48 & 15,2 \\
\hline Não concluiu o curso superior & 39 & 12,3 \\
\hline Não respondeu & 5 & 1,6 \\
\hline Total & 316 & 100,0 \\
\hline
\end{tabular}

Quadro n.2: Escolaridade. Fonte: os autores, 2014.

\section{O aborto na Igreja Mestra}

A posição oficial da Igreja - na perspectiva do que estamos chamando de Igreja Mestra - tem sido muito bem definida nos pronunciamentos recentes do Magistério. O Concílio Vaticano II aborda diretamente a questão do aborto ${ }^{4}$. A Constituição Pastoral Gaudium et Spes se refere a ele em duas situações: no número 27 o aborto aparece entre os crimes contra a pessoa humana:

\footnotetext{
${ }^{4}$ A teologia moral claramente distingue o aborto direto e indireto, condenando o primeiro e aceitando o segundo. No entanto, aborto indireto pode ser lícito apenas em condições que não sejam um aborto no sentido moral. Os casos aceitos sem questionamento têm sido a gravidez ectópica ou tubária - quando a gravidez se localiza fora da cavidade uterina, que é a sede normal de sua implantação e desenvolvimento - e os casos em que o útero precisa ser retirado por alguma doença, como câncer. Nestes casos o objetivo da ação médica é a saúde da mãe, e o aborto ocorre como efeito secundário. Por outro lado Noonan observa que o sacrifício da própria vida será sempre um ato de generosidade, fruto da liberdade, e que não pode ser imposto. (Cf. SANCHES, M.A. O Aborto numa Perspectiva Pastoral. REB - Revista Eclesiástica Brasileira, Fasc. 285, Janeiro, 2012, p.124).
} 
tudo quanto se opõe à vida, como seja toda espécie de homicídio, genocídio, aborto, eutanásia e suicídio voluntário... Todas estas coisas e outras semelhantes são infamantes; ao mesmo tempo que corrompem a civilização humana, desonram mais aqueles que assim procedem, do que os que padecem injustamente; e ofendem gravemente a honra devida ao Criador. (GS, 27)

No número 51 a outra referência ao aborto está no contexto do matrimônio e indica formalmente que o aborto é um crime, pois a vida precisa ser defendida desde o momento da concepção, num diálogo claro com o conhecimento científico atual e abandonando as distinções entre embrião inanimado ou animado - muitas vezes presente nos debates sobre o aborto ao longo da história.

Com efeito, Deus, senhor da vida, confiou aos homens, para que estes desempenhassem dum modo digno dos mesmos homens, o nobre encargo de conservar a vida. Esta deve, pois, ser salvaguardada, com extrema solicitude, desde o primeiro momento da concepção; o aborto e o infanticídio são crimes abomináveis. (GS, 51)

Em 1968 Paulo VI repetiu a condenação tradicional ao aborto na Humanae Vitae. João Paulo II, por sua vez, se torna o papa que vai enfatizar a posição do Magistério da Igreja em relação ao aborto, se pronunciando sobre o tema em vários momentos do seu pontificado e mais claramente na Encíclica Evangelium Vitae onde o aborto é classificado como "crime abominável" $(E V, 58)$, numa clara referência ao mandamento divino: "não matarás" (Dt. 5,17). Neste documento João Paulo II se expressa - com toda consciência e responsabilidade de um sucessor de Pedro: "declaro que o aborto direto, isto é, querido como fim ou como meio, constitui sempre uma desordem moral grave, enquanto morte deliberada de um ser humano inocente." $(\mathrm{EV}, 62)$

É de conhecimento geral na teologia que esta posição do Magistério da Igreja no século XX é fruto de uma longa, embora nem sempre consensual, tradição cristã sobre o assunto ${ }^{5}$. A condenação do aborto está claramente colocada em documentos do primeiro século do cristianismo como na Didaque.

\footnotetext{
${ }^{5}$ Em nenhum momento o Magistério da Igreja aprovou o aborto, mas por influência da dificuldade de se definir o início da vida, houve momento em que ele condenava com mais rigor, com penitências mais severas, se o aborto ocorresse depois do feto estar 'animado'. (Cf. SANCHES, M.A. VIERIA, J.O; MELO, E.A. A dignidade do embrião humano. SP: Ave Maria, 2012, p.50).
} 
O texto apresenta a seguinte exortação: "não mate a criança no seio da mãe, nem depois que ela tenha nascido" (n.2,2), seguida pela Carta de Barnabé "Não farás morrer a criança no seio da mãe; tampouco a matarás após o nascimento" (XIX, $\mathrm{n}^{\mathrm{o}} .5$ ). Nos primeiros séculos do cristianismo os escritores concordam que o aborto é uma violação do amor devido ao próximo. "A cultura da época aceitava o aborto. Os cristãos, pessoas deste mundo Greco-Romano e o Evangelho, condenaram-no." 6

Por fim, a posição da Igreja Mestra, em relação ao aborto, é bem consolidada e representa uma força profética nos nossos tempos onde o valor da vida humana passa por um processo de relativização. A legalização do aborto é causa e fruto de uma mudança paradigmática na sociedade atual, onde o bem estar de alguns se consegue às custas de sacrifícios de muitos. Deste modo a Igreja convoca o mundo católico, independentemente do ordenamento jurídico do país onde vive, a assumir junto com o Magistério a posição de que o aborto é inaceitável e configura um grave problema moral.

Neste aspecto é interessante observar que os dados da pesquisa revela uma grande sintonia dos agentes de pastoral com o posicionamento desta Igreja Mestra, embora as respostas dos agentes não revelem uma sintonia perfeita, pois 6,3\% se posicionaram a favor do aborto e de sua legalização, $77,2 \%$ contra o aborto e contra a legalização e $12,7 \%$ contra o aborto, mas a favor de sua legalização.

A pesquisa nos permitiu cruzar dados que revelam dissonâncias quanto à percepção de gênero, revelando uma maior percentagem de mulheres $(79,7 \%)$ contra o aborto e contra a legalização, enquanto que quase $17,9 \%$ dos homens se posicionaram contra o aborto, mas a favor da legalização, contra 9,9\% das mulheres. $\mathrm{O}$ quadro $\mathrm{n} .3$ detalha estas divergências.

\footnotetext{
${ }^{6}$ NOONAN JR. John Thomas. The morality of abortion: legal and historical perspectives. Harvard University Press / Cambridge, Massachusetts, 1970, p.18.
} 


\begin{tabular}{|l|c|c|c|c|}
\hline \multirow{2}{*}{ Gênero } & \multicolumn{4}{|c|}{ Quanto à legalização do aborto } \\
\cline { 2 - 5 } & $\begin{array}{c}\text { A favor do } \\
\text { aborto e sua } \\
\text { legalização }\end{array}$ & $\begin{array}{c}\text { Contra o aborto } \\
\text { e contra a } \\
\text { legalização }\end{array}$ & $\begin{array}{c}\text { Contra o aborto } \\
\text { mas a favor } \\
\text { de sua legalização }\end{array}$ & $\begin{array}{c}\text { Não } \\
\text { respondeu }\end{array}$ \\
\hline Feminino & $6,4 \%$ & $79,7 \%$ & $9,9 \%$ & $4,0 \%$ \\
\hline Masculino & $6,3 \%$ & $72,3 \%$ & $17,9 \%$ & $3,6 \%$ \\
\hline Total & $6,3 \%$ & $77,2 \%$ & $12,7 \%$ & $3,8 \%$ \\
\hline
\end{tabular}

Quadro n.3: Legalização do aborto / gênero. Fonte: os autores, 2014.

Quanto às faixas etárias também diferentes posições surgem, como vemos no quadro n. 4, mostrando uma clara tendência das pessoas de mais idade se manifestarem mais contra a legalização do aborto do que os mais jovens. Estes permanecem contra o aborto, mas quase $20 \%$ são a favor da sua legalização.

\begin{tabular}{|l|c|c|c|c|}
\hline \multirow{2}{*}{ Faixa etária } & \multicolumn{4}{|c|}{ Quanto a legalização do aborto } \\
\cline { 2 - 5 } & $\begin{array}{l}\text { A favor do } \\
\text { aborto e sua } \\
\text { legalização }\end{array}$ & $\begin{array}{l}\text { Contra o aborto } \\
\text { e contra a } \\
\text { legalização }\end{array}$ & $\begin{array}{l}\text { Contra o aborto } \\
\text { mas a favor de } \\
\text { sua legalização }\end{array}$ & $\begin{array}{l}\text { Não } \\
\text { respondeu }\end{array}$ \\
\hline Entre 18 e 30 anos & $16,3 \%$ & $61,6 \%$ & $19,8 \%$ & $2,3 \%$ \\
\hline Entre 31 e 50 anos & $2,1 \%$ & $83,6 \%$ & $11,6 \%$ & $2,7 \%$ \\
\hline Acima de 50 anos & $4,1 \%$ & $89,2 \%$ & $6,8 \%$ &, $0 \%$ \\
\hline Total & $6,3 \%$ & $77,1 \%$ & $12,7 \%$ & $3,8 \%$ \\
\hline
\end{tabular}

Quadro n.4: Legalização do aborto / faixa etária. Fonte: os autores, 2014.

É muito interessante observar que as experiências vivenciadas no relacionamento influenciam as opiniões das pessoas em relação a este posicionamento, pois cruzando os dados com a questão do estado civil temos o quadro n. 5 com destaque para a alta percentagem de pessoas a favor do aborto, quando estão vivendo uma união estável $(27,8 \%)$, que se somando à terceira posição, chega-se a mais de $55 \%$ a favor da legalização do aborto. É 
sem dúvida notável perceber esta relação entre "viver em união estável" e "ser a favor da legalização do aborto".

\begin{tabular}{|l|c|c|c|c|}
\hline \multirow{2}{*}{ Estado Civil } & \multicolumn{4}{|c|}{ Quanto a legalização do aborto } \\
\cline { 2 - 5 } & $\begin{array}{l}\text { A favor do aborto } \\
\text { e sua legalização }\end{array}$ & $\begin{array}{l}\text { Contra o aborto } \\
\text { e contra a } \\
\text { legalização }\end{array}$ & $\begin{array}{l}\text { Contra o aborto } \\
\text { mas a favor de } \\
\text { sua legalização }\end{array}$ & $\begin{array}{l}\text { Não } \\
\text { respondeu }\end{array}$ \\
\hline Solteiro & $15,4 \%$ & $59,6 \%$ & $19,2 \%$ & $5,8 \%$ \\
\hline Casado & $2,5 \%$ & $83,7 \%$ & $9,9 \%$ & $4,0 \%$ \\
\hline Viúvo &, $0 \%$ & $94,4 \%$ & $5,6 \%$ &, $0 \%$ \\
\hline União Estável & $27,8 \%$ & $44,4 \%$ & $27,8 \%$ &, $0 \%$ \\
\hline Divorciado & $15,4 \%$ & $76,9 \%$ &, $0 \%$ & $7,7 \%$ \\
\hline Total & $6,3 \%$ & $77,2 \%$ & $12,7 \%$ & $3,8 \%$ \\
\hline
\end{tabular}

Quadro n.5: Legalização do aborto / estado civil. Fonte: os autores, 2014.

É importante observar que o tempo de inserção na pastoral influencia as pessoas, o que é de se esperar, na sua postura frente a estas questões, de modo que dentre as pessoas com menos de 1 ano de atuação pastoral $11,8 \%$ se posiciona a favor do aborto enquanto a percentagem cai para $1 \%$ entre as pessoas com mais de 3 anos de inserção nestas pastorais, como mostra o quadro n. 6 . Aqui podemos dizer que as pastorais desempenham o seu papel de divulgar o ensinamento da Igreja e formar os agentes a partir dele.

\begin{tabular}{|l|c|c|c|c|}
\hline \multirow{2}{*}{$\begin{array}{l}\text { Tempo de atuação } \\
\text { na Pastoral }\end{array}$} & \multicolumn{4}{|c|}{ Quanto a legalização do aborto } \\
\cline { 2 - 5 } & $\begin{array}{l}\text { A favor do } \\
\text { aborto e sua } \\
\text { legalização }\end{array}$ & $\begin{array}{l}\text { Contra o aborto } \\
\text { e contra a } \\
\text { legalização }\end{array}$ & $\begin{array}{l}\text { Contra o aborto } \\
\text { mas a favor de } \\
\text { sua legalização }\end{array}$ & $\begin{array}{l}\text { Não } \\
\text { respondeu }\end{array}$ \\
\hline Menos de 1 ano & $11,8 \%$ & $69,9 \%$ & $17,2 \%$ & $1,1 \%$ \\
\hline Entre 1 e 3 anos & $4,9 \%$ & $77,5 \%$ & $11,8 \%$ & $5,9 \%$ \\
\hline Mais de 3 anos & $1,0 \%$ & $84,0 \%$ & $11,0 \%$ & $4,0 \%$ \\
\hline Total & $6,3 \%$ & $77,1 \%$ & $12,7 \%$ & $3,8 \%$ \\
\hline
\end{tabular}

Quadro n. 6: Legalização do aborto / tempo de atuação. Fonte: os autores, 2014. 
No item abaixo passamos a situar a postura da Igreja em relação às pessoas que praticaram o aborto e na sequência iremos analisar os resultados da pesquisa a respeito desta postura.

\section{O aborto numa Igreja Mãe}

O mesmo estudo dos documentos da Igreja que revela uma clara posição de condenação do aborto, também indica que o Magistério da Igreja manifesta claramente a sua preocupação pastoral ao explicitar uma posição de acolhida às pessoas que praticaram o aborto. Por mais que esta postura da Igreja - que chamamos aqui de Igreja Mãe - esteja expressa em inúmeras declarações do Magistério a sociedade brasileira parece não receber esta mensagem com a mesma força que percebe a da Igreja Mestra.

Para desenvolver a posição que revela esta Igreja Mãe podemos iniciar pelo mais recente documento da Igreja na América Latina e Caribe - o Documento de Aparecida - que, em sintonia com o Sumo Pontífice, exorta todos a "acolher com misericórdia aquelas que abortaram, para ajudá-las a curar suas graves feridas e convidá-las a ser defensoras da vida." (DAp,469) Esta exortação a 'acolher com misericórdia aquelas que abortaram' nasce da compreensão de que a mulher que praticou o aborto muitas vezes é uma vítima - e como tal ela sofre a situação, mais do que a promove - ou se torna uma vítima de seu ato ao praticá-lo. "O aborto faz duas vítimas: por certo a criança, mas também a mãe" (469). A Igreja na América Latina tem consciência de que oferece um "serviço de caridade" (98) aos povos deste Continente e, em situações concretas precisa ser rápida em prestar serviço e lenta no julgamento, manifestando ciência de que está inserida num contexto dramático, como os dados indicam:

Segundo estimativas da Organização Mundial de Saúde, metade das gestações é indesejada, com uma a cada nove mulheres recorrendo ao abortamento para interrompê-las. Estima-se que na América Latina e no Caribe ocorram anualmente 18 milhões de gestações, sendo que destas $52 \%$ não foram planejadas, com $23 \%$ terminando em abortamento (AGI, 1999). Para o Brasil, calcula-se que $31 \%$ das gestações terminam em abortamento. $^{7}$

\footnotetext{
${ }^{7}$ BRASIL, MINISTÉRIO DA SAÚDE. Atenção Humanizada ao Abortamento: norma técnica. Brasília: Ministério da Saúde, 2005, p.7.
} 
O papa João Paulo II, no mesmo documento onde ele confirma a posição de condenação do aborto, a Evangelium Vitae, ele demonstra conhecimento do drama em torno do aborto, assumindo a face da Igreja Mãe, assim se expressa:

Um pensamento especial quereria reservá-lo para vós, mulheres, que recorrestes ao aborto. A Igreja está a par dos numerosos condicionalismos que poderiam ter influído sobre a vossa decisão, e não duvida que, em muitos casos, se tratou de uma decisão difícil, talvez dramática. Provavelmente a ferida no vosso espírito ainda não está sarada. (EV, n. 99)

E faz isto, sem negar a crueldade do aborto, mas como um serviço de caridade que acolhe e promove as pessoas, oferecendo para elas o bem mais precioso da Igreja, o perdão, num momento em que elas precisam de ânimo e esperança:

$\mathrm{Na}$ realidade, aquilo que aconteceu, foi e permanece profundamente injusto. Mas não vos deixeis cair no desânimo, nem percais a esperança. Sabei, antes, compreender o que se verificou e interpretai-o em toda a sua verdade. Se não o fizestes ainda, abri-vos com humildade e confiança ao arrependimento: o Pai de toda a misericórdia espera-vos para vos oferecer o seu perdão e a sua paz no sacramento da Reconciliação. (EV, 99)

Esta posição do Magistério da Igreja reafirma um ponto central da moral católica em sua preocupação pastoral, que faz a distinção entre a moralidade do ato praticado e a pessoa que o praticou, rejeitando o erro e acolhendo as pessoas. A atitude de acolhida à mulher que praticou o aborto pode se tornar uma medida eficaz contra o aborto, pois há estudo que indica que dentre as mulheres que praticaram aborto " $12 \%$ já haviam feito aborto antes". 8

$\mathrm{Na}$ pesquisa de campo realizada gostaríamos também de identificar se a comunidade percebe esta complexidade da posição da Igreja em relação ao aborto, ou seja, se revela também a face da Igreja Mãe. É o que a questão abaixo busca captar indagando a respeito do modo como os agentes de pastoral se posicionam quanto às pessoas que fizeram aborto. Novamente as respostas estão indicando uma grande sintonia ao ensinamento da Igreja por parte dos agentes de pastoral entrevistados. Vejamos os resultados: $6 \%$ dos agentes

\footnotetext{
${ }^{8}$ SANDI, Stella de Faro e BRAZ, Marlene. As mulheres brasileiras e o aborto: uma abordagem bioética na saúde pública. Revista Bioética, 2010; vol. 18 n.1, Brasília: CFM, p. 135.
} 
das pastorais respondeu que as pessoas que praticaram aborto não podem se denominar católicas; $4,4 \%$ respondeu também de modo intolerante que estas pessoas não poderiam ser acolhidas pela comunidade católica. No entanto $26,7 \%$ respondeu que sendo católicas essas pessoas precisam da ajuda da Igreja e 61\% indicou a posição que consideramos mais ativa em termos de acolhida, respondendo que estas pessoas precisam saber que a Igreja quer acolhê-las e perdoá-las.

Para este item as questões de gênero, escolaridade e estado civil não apresentaram diferenças significativas. No entanto, a diferença de faixa etária mostrou diversidade relevante sendo que apenas $5,8 \%$ das pessoas com idade entre 18 e 30 anos indicou uma postura de exclusão, contra quase o dobro $(10,8 \%)$ entre as pessoas com idade acima de 50 anos. O quadro n. 7, também revela que $71 \%$ dos entrevistados com idade entre 31 e 50 anos assumiu uma postura de acolhida que consideramos mais ativa, revelando mais claramente a face da Igreja Mãe. É interessante observar a diversidade de respostas relacionadas às faixas etárias.

\begin{tabular}{|c|c|c|c|c|c|}
\hline \multirow{2}{*}{ Faixa Etária } & \multicolumn{5}{|c|}{ Quanto às pessoas que fizeram aborto } \\
\cline { 2 - 6 } & $\begin{array}{l}\text { Não } \\
\text { poderiam se } \\
\text { denominar } \\
\text { católicas }\end{array}$ & $\begin{array}{l}\text { Não } \\
\text { poderiam ser } \\
\text { acolhidas pela } \\
\text { comunidade }\end{array}$ & $\begin{array}{l}\text { Sendo } \\
\text { católicas } \\
\text { precisam } \\
\text { da ajuda } \\
\text { da Igreja }\end{array}$ & $\begin{array}{l}\text { Precisam } \\
\text { saber que a } \\
\text { Igreja quer } \\
\text { acolhê-las e } \\
\text { perdoá-las }\end{array}$ & $\begin{array}{l}\text { Não } \\
\text { Respondeu }\end{array}$ \\
\hline Entre 18 e 30 anos & $5,8 \%$ & $3,5 \%$ & $29,1 \%$ & $61,6 \%$ &, $0 \%$ \\
\hline Entre 31 e 50 anos & $3,4 \%$ & $1,4 \%$ & $19,9 \%$ & $71,9 \%$ & $3,4 \%$ \\
\hline Acima de 50 anos & $10,8 \%$ & $5,4 \%$ & $37,8 \%$ & $44,6 \%$ & $1,4 \%$ \\
\hline Total & $6,0 \%$ & $4,4 \%$ & $26,7 \%$ & $61,0 \%$ & $1,9 \%$ \\
\hline
\end{tabular}

Quadro n.7: Quanto às pessoas que fizeram o aborto. Fonte: os autores, 2014.

Curiosamente as pessoas com menos tempo de atividade pastoral apresentam uma postura de maior acolhida do que as pessoas que estão há mais de três anos na atividade pastoral. A diferença é notável sendo que dentre as pessoas recém-chegadas à pastoral $5,4 \%$ assumem uma postura de não acolhimento enquanto que esta percentagem sobe para $14 \%$ entre as pessoas com 
mais de 3 anos de inserção pastoral. Isto nos parece grave, pois revela que a atividade pastoral está afastando as pessoas da face materna da Igreja. Talvez aqui as pastorais envolvidas tenham dificuldade de formar as pessoas contra o aborto, como vimos acima, conciliando com o ensinamento de acolhida e misericórdia, ou seja, ao se formar para a perspectiva da Igreja Mestra se perde a perspectiva da Igreja Mãe. Vejam os números no quadro n. 8 .

\begin{tabular}{|c|c|c|c|c|c|}
\hline \multirow{2}{*}{$\begin{array}{l}\text { Tempo de atuação } \\
\text { nas pastorais }\end{array}$} & $\begin{array}{l}\text { Não } \\
\text { poderiam se } \\
\text { denominar } \\
\text { católicas }\end{array}$ & $\begin{array}{l}\text { Não poderiam } \\
\text { ser acolhidas } \\
\text { pela comunidade }\end{array}$ & $\begin{array}{l}\text { Sendo católicas } \\
\text { precisam da } \\
\text { ajuda da Igreja }\end{array}$ & $\begin{array}{l}\text { Precisam saber } \\
\text { que a Igreja quer } \\
\text { acolhê-las e } \\
\text { perdoá-las }\end{array}$ & $\begin{array}{l}\text { Não } \\
\text { Respondeu }\end{array}$ \\
\hline Menos de 1 ano & $4,3 \%$ & $1,1 \%$ & $33,3 \%$ & $60,2 \%$ & $1,1 \%$ \\
\hline Entre 1 e 3 anos & $4,9 \%$ & $6,9 \%$ & $26,5 \%$ & $60,8 \%$ & $1,0 \%$ \\
\hline Mais de 3 anos & $8,0 \%$ & $6,0 \%$ & $22,0 \%$ & $62,0 \%$ & $2,0 \%$ \\
\hline Total & $6,0 \%$ & $4,4 \%$ & $27,0 \%$ & $60,6 \%$ & $1,9 \%$ \\
\hline
\end{tabular}

Quadro n.8: Quanto às pessoas que fizeram o aborto/ tempo de atuação.

Fonte: os autores, 2014.

\section{A responsabilidade pelo aborto}

Quando a Igreja vê a mulher que pratica o aborto como vítima ela manifesta uma clara percepção da realidade social que promove uma "cultura da morte" (EV, 12) com situações viciadas por uma cultura de "permissividade hedonista e de machismo agressivo". É neste contexto que João Paulo II se pronuncia também na Carta às Mulheres: "Nestas condições, a escolha do aborto, que permanece sempre um pecado grave, antes de ser uma responsabilidade atribuível à mulher, é um crime que deve ser imputado ao homem e à cumplicidade do ambiente circundante" $(\mathrm{CM}, 5)$. Este pronunciamento de João Paulo II demonstra que a Igreja tem uma visão da complexidade dos contextos sociais que levam ao aborto, e indica que atribuir a responsabilidade do aborto primeiramente à mulher seria injusto, e refletiria uma visão reducionista que ocultaria - e ocultando inocenta - os outros agentes morais envolvidos na 
problemática do aborto. Aqui a Igreja, e junto com ela muitos movimentos feministas, se pergunta: Onde está o homem? Ou será que a mulher engravidou sozinha? Qual a atitude do homem quando soube que sua companheira estava grávida? O aborto começa a ocorrer quando um homem não assume a paternidade e diz para sua companheira que 'isto é problema dela'. João Paulo II deixa claro que a responsabilidade do aborto - em tal situação - é antes atribuível a este homem do que à mulher. No diálogo com movimentos feministas ouvimos uma frase que faz eco a este posicionamento, vinda de uma líder do movimento: "toda vez que um homem assume uma mulher não aborta”. A frase é, sem dúvida, muito generalizante, mas concordamos que na grande maioria das vezes que uma mulher abortou foi porque um homem não assumiu a paternidade, pois, sem dúvida, o machismo, traço da nossa cultura que resiste à evangelização, é uma das causas do aborto no Brasil. ${ }^{9}$

Indicamos acima que já está presente no pensamento da Igreja que, em muitas situações em que ocorre o aborto o homem é o primeiro responsável pelo ocorrido. Se isto se aplica às situações onde a mulher foi abandonada, enganada, rejeitada e deixada sozinha para assumir uma gravidez, certamente se aplica com mais força ainda quando o aborto é praticado por uma mulher que foi violentada. Por isso, além do amplo impacto que a afirmação de João Paulo II, na Carta às Mulheres, tem sobre toda situação do aborto, estamos compreendendo aqui que a frase de que o aborto "antes de ser uma responsabilidade atribuível à mulher, é um crime que deve ser imputado ao homem" $(\mathrm{CM}, 5)$, se aplica ainda com mais força às situações onde a mulher aborta por ter sido violentada.

Outras passagens dos documentos da Igreja já demonstravam o reconhecimento de que a mulher, muitas vezes aborta sobre pressão. "A mulher, não raro, é sujeita a pressões tão fortes que se sente psicologicamente constrangida a ceder ao aborto" $(E V, 59)$. Este trecho não se refere exclusivamente ao caso de estupro, mas, certamente sofrer violência sexual é um forte fator que constrange a mulher a "ceder ao aborto", lembrando a reflexão da teologia moral reconhecendo que há situações onde a pessoa "se torna incapaz de lidar com certos imperativos morais". ${ }^{10}$ A passagem da Evangelium Vitae também conclui que,

\footnotetext{
${ }^{9}$ SANDI, Stella de Faro e BRAZ, Marlene. As mulheres brasileiras e o aborto: uma abordagem bioética na saúde pública. Revista Bioética, 2010; vol. 18 n.1, Brasília: CFM, p. 138.

${ }^{10}$ HARING, Bernard. A theological evaluation. In: NOONAN JR. John Thomas. The morality of abortion: legal and historical perspectives. Harvard University Press / Cambridge, Massachusetts, 1970, p. 140.
} 
nestes casos, a responsabilidade moral do aborto "pesa particularmente sobre aqueles que direta ou indiretamente a forçaram a abortar" (EV,59).

O papa fala também da responsabilidade do 'ambiente circundante' - e assim ele traz para o contexto do debate sobre o aborto, o papel da família, da comunidade e do Estado. ${ }^{11}$ A família - principalmente os pais da mulher e do homem que pratica o aborto - pode assumir atitudes irresponsáveis frente à notícia de uma gravidez: indiferença, não aceitação, rejeição e até pressão para que o aborto ocorra para salvar a 'honra' da família. Aqui poderíamos parafrasear a líder feminista: 'na grande maioria das vezes em que uma família assume um aborto não ocorre'.

A Igreja - como comunidade - está chamando a si também a responsabilidade e quer desenvolver em seu seio uma postura que possibilite "apoiar e acompanhar pastoralmente e com especial ternura e solidariedade as mulheres que decidiram não abortar", esperançosa de que o desenvolvimento da acolhida com ternura e solidariedade leve muitas mulheres a não "ceder ao aborto". O acolhimento com misericórdia daquelas que abortaram pode criar nelas condições para que não abortem novamente, mais ainda, a Igreja acredita que elas possam se tornar agentes de pastoral em nossas comunidades, como autênticas "defensoras da vida" (DAp, 469). Isto se reveste de atos concretos, como na família, os pais apoiando sempre as filhas e filhos que engravidam independente do contexto; enfatizando no trabalho pastoral que os homens e mulheres têm igual responsabilidade perante o planejamento familiar e acolhida dos filhos; desenvolvendo estruturas comunitárias para apoiar integralmente as grávidas desamparadas; desenvolvendo estruturas comunitárias de acolhida e apoio espiritual e psicológico para mulheres que abortaram.

No Diretório da Pastoral Familiar, um dos objetivos da pastoral familiar consta como sendo o de "promoção e defesa da vida" (11). O documento orienta ainda para que os agentes pastorais tenham uma preparação específica e contínua, para que possam orientar e prestar ajuda às mulheres que "praticaram aborto e oferecer uma atitude misericordiosa que permita, a quem sofre por causa desse ato nefasto, a adquirir a determinação de não voltar a praticá-lo" (110).

Sobre este ponto de indicar responsabilidade sobre o aborto a pesquisa de campo se mostrou complexa. Há uma percepção das múltiplas responsabilidades sobre o aborto, mas fica evidente o machismo da nossa sociedade, pois a atribuição de responsabilidade da mulher sobre o aborto é quatro vezes maior

${ }^{11}$ Também na Evangelium Vitae n. 59 João Paulo II amplia a responsabilidade do aborto para a família, os legisladores, os que promovem uma mentalidade hedonista, enfim toda a sociedade. 
do que a masculina. Certamente temos, neste ponto, o maior desencontro entre o que os documentos oficiais da Igreja orientam e a percepção dos agentes de pastoral, revelado nesta pesquisa. Assim, frente à questão quem é o principal responsável pelo aborto? Obtivermos os seguintes resultados: $25,2 \%$ respondeu que a mulher é a principal responsável pelo aborto; $27,8 \%$ que a responsabilidade é da família que não apoiou; $33,2 \%$ que a responsabilidade é da comunidade/sociedade; e apenas $6,4 \%$ que a responsabilidade é do homem que não deu apoio. Curiosamente $14 \%$ não respondeu.

As respostas de gênero apresentaram diferenças significativas sobre esta questão: as mulheres responsabilizando mais a família (31,5\%) e os homens responsabilizando mais a comunidade/sociedade (42,3\%). É curioso que a baixa atribuição de responsabilidade masculina sobre o aborto é ainda menor entre as mulheres, $5,5 \%$, contra $8,1 \%$ entre os próprios homens. Confere no quadro n.9.

\begin{tabular}{|l|c|c|c|c|c|}
\hline \multirow{2}{*}{ Gênero } & \multicolumn{5}{|c|}{ Responsável pelo aborto } \\
\cline { 2 - 6 } & $\begin{array}{l}\text { A mulher que } \\
\text { fez o aborto }\end{array}$ & $\begin{array}{l}\text { A família que } \\
\text { não apoiou }\end{array}$ & $\begin{array}{l}\text { O homem que } \\
\text { não apoiou }\end{array}$ & $\begin{array}{l}\text { A comunidade/ } \\
\text { sociedade }\end{array}$ & $\begin{array}{l}\text { Não } \\
\text { respondeu }\end{array}$ \\
\hline Feminino & $26,5 \%$ & $31,5 \%$ & $5,5 \%$ & $28,5 \%$ & $8,0 \%$ \\
\hline Masculino & $23,4 \%$ & $20,7 \%$ & $8,1 \%$ & $42,3 \%$ & $5,4 \%$ \\
\hline Total & $25,2 \%$ & $27,8 \%$ & $6,4 \%$ & $33,2 \%$ & $7,3 \%$ \\
\hline
\end{tabular}

Quadro n.9: Responsabilidade pelo aborto / gênero. Fonte: os autores, 2014.

A questão do estado civil se apresentou controvertida em relação à atribuição de responsabilidade pelo aborto. Os solteiros são os que mais responsabilizam as mulheres $(28,8 \%)$ enquanto os divorciados são os que menos as responsabilizam $(15,4 \%)$ e os que mais responsabilizam a comunidade/sociedade $(53,8 \%)$. O grupo que vive em união estável é o que mais responsabiliza a família $(44,4 \%)$ e os que menos atribuem esta responsabilidade à comunidade $(22,2 \%)$. É entre os casados que se encontram os que menos responsabilizam o homem pelo aborto (5,5\%). Podemos ver estes e outros números no quadro n. 10. 


\begin{tabular}{|l|c|c|c|c|c|}
\hline \multirow{2}{*}{ Estado Civil } & \multicolumn{5}{|c|}{ Responsável pelo aborto } \\
\cline { 2 - 6 } & $\begin{array}{l}\text { A mulher que } \\
\text { fez o aborto }\end{array}$ & $\begin{array}{l}\text { A família que } \\
\text { não apoiou }\end{array}$ & $\begin{array}{l}\text { O homem que } \\
\text { não apoiou }\end{array}$ & $\begin{array}{l}\text { A comunidade/ } \\
\text { sociedade }\end{array}$ & $\begin{array}{l}\text { Não } \\
\text { respondeu }\end{array}$ \\
\hline Solteiro & $28,8 \%$ & $23,1 \%$ & $7,7 \%$ & $30,8 \%$ & $9,6 \%$ \\
\hline Casado & $26,6 \%$ & $27,1 \%$ & $5,5 \%$ & $33,2 \%$ & $7,5 \%$ \\
\hline Viúvo & $27,8 \%$ & $33,3 \%$ & $5,6 \%$ & $33,3 \%$ &, $0 \%$ \\
\hline União Estável & $22,2 \%$ & $44,4 \%$ & $11,1 \%$ & $22,2 \%$ &, $0 \%$ \\
\hline Divorciado & $15,4 \%$ & $15,4 \%$ & $7,7 \%$ & $53,8 \%$ & $7,7 \%$ \\
\hline Total & $25,2 \%$ & $27,8 \%$ & $6,4 \%$ & $33,2 \%$ & $7,3 \%$ \\
\hline
\end{tabular}

Quadro n.10: Responsabilidade pelo aborto / Estado civil. Fonte: os autores, 2014.

Esta questão mostra que os agentes das pastorais envolvidos não estão em sintonia com o pensamento e as orientações da Igreja sobre este ponto. Pois eles praticamente isentam o homem de sua responsabilidade em relação ao aborto. O homem e a sociedade são apontados como responsáveis diretos pelo aborto nos documentos oficiais da Igreja e isto revela a mudança de mentalidade pela qual o Magistério da Igreja vem passando nas últimas décadas. O (DAp,452) defende que a relação entre o homem e a mulher "é de reciprocidade e colaboração mútua". E o mesmo documento chama a atenção, também, para a mentalidade "machista" que ignora a novidade do cristianismo, "onde se proclama a igual dignidade e responsabilidade da mulher em relação ao homem" (DAp, 453). Desta forma a Igreja por meio de seus documentos não isenta a mulher da responsabilidade sobre o aborto, mas nomeia também os outros responsáveis que durante muito tempo foram deixados de fora deste grave problema que atinge todas as sociedades.

O quadro que cruza os dados sobre escolaridade e responsabilidade sobre o aborto apresentou índices controversos e de difícil análise. A diferença mais significativa se mostra no grupo de pessoas que não concluiu a 4 série, pois foi o grupo que atribuiu maior responsabilidade do aborto ao homem $(12,5 \%)$, comparado com $4,3 \%$ no grupo de pessoas que concluíram curso superior, conforme o quadro 11 . 


\begin{tabular}{|l|c|c|c|c|c|}
\hline \multirow{2}{*}{ Escolaridade } & \multicolumn{5}{|c|}{ Responsável pelo aborto } \\
\cline { 2 - 6 } & $\begin{array}{l}\text { A mulher que } \\
\text { fez o aborto }\end{array}$ & $\begin{array}{l}\text { A família que } \\
\text { não apoiou }\end{array}$ & $\begin{array}{l}\text { O homem que } \\
\text { não apoiou }\end{array}$ & $\begin{array}{l}\text { A comunidade/ } \\
\text { sociedade }\end{array}$ & $\begin{array}{l}\text { Não } \\
\text { respondeu }\end{array}$ \\
\hline $\begin{array}{l}\text { Não concluiu } \\
\text { a 4 série }\end{array}$ & $20,8 \%$ & $33,3 \%$ & $12,5 \%$ & $29,2 \%$ & $4,2 \%$ \\
\hline Concluiu a 4 série & $24,4 \%$ & $26,8 \%$ & $7,3 \%$ & $39,0 \%$ & $2,4 \%$ \\
\hline $\begin{array}{l}\text { Concluiu o ensino } \\
\text { fundamental }\end{array}$ & $26,1 \%$ & $43,5 \%$ & $2,2 \%$ & $21,7 \%$ & $6,5 \%$ \\
\hline $\begin{array}{l}\text { Concluiu o } \\
\text { ensino médio }\end{array}$ & $29,7 \%$ & $27,0 \%$ & $6,3 \%$ & $25,2 \%$ & $11,7 \%$ \\
\hline $\begin{array}{l}\text { Concluiu o } \\
\text { curso superior }\end{array}$ & $25,5 \%$ & $21,3 \%$ & $4,3 \%$ & $42,6 \%$ & $6,4 \%$ \\
\hline $\begin{array}{l}\text { Não concluiu } \\
\text { o curso superior }\end{array}$ & $17,9 \%$ & $20,5 \%$ & $5,1 \%$ & $53,8 \%$ & $2,6 \%$ \\
\hline Total & $25,2 \%$ & $27,8 \%$ & $6,4 \%$ & $33,2 \%$ & $7,3 \%$ \\
\hline
\end{tabular}

Quadro n.11: Responsabilidade pelo aborto / escolaridade. Fonte: os autores, 2014.

Cruzando os dados da responsabilidade pelo aborto com a condição de tempo de atuação nas pastorais se percebe alguns movimentos. A atribuição de responsabilidade da mulher pelo aborto vai baixando na medida em que a pessoa tem mais anos de atividade pastoral e atribuição de responsabilidade masculina sobre o aborto vai aumentando. É curioso que o papel da família nesta questão faz o caminho inverso, vista como mais responsável pelas pessoas que estão chegando nas pastorais $(38,0 \%)$ e cai para $25 \%$ para as pessoas que estão nas pastorais há mais de 3 anos, conforme o quadro 12 .

\begin{tabular}{|l|c|c|c|c|c|}
\hline \multirow{2}{*}{$\begin{array}{l}\text { Tempo de atuação } \\
\text { na Pastoral }\end{array}$} & \multicolumn{5}{|c|}{ Responsável pelo aborto } \\
\cline { 2 - 6 } & $\begin{array}{l}\text { A mulher que } \\
\text { fez o aborto }\end{array}$ & $\begin{array}{l}\text { A família que } \\
\text { não apoiou }\end{array}$ & $\begin{array}{l}\text { O homem que } \\
\text { não apoiou }\end{array}$ & $\begin{array}{l}\text { A comunidade/ } \\
\text { sociedade }\end{array}$ & $\begin{array}{l}\text { Não } \\
\text { respondeu }\end{array}$ \\
\hline Menos de 1 ano & $26,1 \%$ & $38,0 \%$ & $2,2 \%$ & $27,2 \%$ & $6,5 \%$ \\
\hline Entre 1 e 3 anos & $23,0 \%$ & $25,0 \%$ & $7,0 \%$ & $42,0 \%$ & $3,0 \%$ \\
\hline Mais de 3 anos & $22,0 \%$ & $25,0 \%$ & $8,0 \%$ & $34,0 \%$ & $11,0 \%$ \\
\hline Total & $25,3 \%$ & $27,6 \%$ & $6,4 \%$ & $33,3 \%$ & $7,4 \%$ \\
\hline
\end{tabular}

Quadro n. 12: Responsabilidade pelo aborto / tempo de atuação. Fonte: os autores, 2014. 


\section{Conclusão}

De acordo com a pesquisa os espaços de atuação da Igreja Católica, no âmbito das pastorais estudadas, mostraram grande consistência entre a doutrina e a ação pastoral, com alguns desencontros. Queremos destacar a relevância da pesquisa em cruzar os dados gerais com as categorias que identificavam os entrevistados, pois só assim consegue-se identificar os setores onde uma maior sintonia é percebida, bem como os setores onde há um maior distanciamento entre a posição da Igreja e a percepção dos agentes de pastoral. Por isto nesta conclusão vamos apenas retomar os setores onde houve maior proximidade e os setores onde o distanciamento foi maior.

Um grande distanciamento entre o que a Igreja ensina e a percepção dos agentes se percebeu na faixa etária entre 18 e 30 anos onde $36,1 \%$ se posiciona a favor da legalização do aborto, o que indica que a mentalidade a favor da legalização do aborto está mais presente nas novas gerações, pois acima de 50 anos a posição é bem diferente sendo que apenas 10,9\% assume a mesma posição. Neste mesmo item a maior sintonia com o ensinamento se encontra entre os casados, visto que entre eles apenas $2,5 \%$ se posiciona a favor do aborto, posição que é valorizada nesta pesquisa, pois a maioria dos entrevistados $(63,9 \%)$ era casada.

Quando observamos a mudança de postura dos agentes de pastoral ao longo da sua inserção nas atividades pastorais podemos identificar movimentos complexos. Os agentes de pastorais com mais de três anos de atividades se mostraram: a) menos a favor do aborto, b) com menos disposição de acolher as pessoas que abortaram, c) atribuindo maior responsabilidade ao homem pelo aborto. Podemos dizer que os movimentos percebidos em ' $a$ ' e 'c' refletem um bom trabalho de busca de sintonia com o pensamento do Magistério, mas que o item 'b' expressa a dificuldade de se perceber a dimensão da Igreja Mãe. Curiosamente as pessoas com menos de 1 ano de pastoral tem uma maior postura de acolhida (93,5\%), enquanto as pessoas com mais de 3 anos já perderam um pouco esta sensibilidade (84\%). Neste ponto as pastorais afastam as pessoas do ensinamento do Magistério.

Como último ponto de reflexão, dentre outros que podem ser feitos, fica a constatação de que a comunidade percebe e reflete o pensamento da Igreja a respeito da múltipla responsabilidade sobre o aborto, mas infelizmente a percepção da responsabilidade masculina ainda é pequena. O perfil de resposta mais sintomático neste aspecto se deu entre os casados, pois eles dividem as 
responsabilidades pelo aborto entre as mulheres $(26,6 \%)$, a família $(27 \%)$ e a comunidade $(33,2 \%)$ de modo bastante equilibrado, no entanto a responsabilidade masculina é quase negada $(5,5 \%)$, num flagrante contraponto à luta da Igreja pela igual responsabilidade de homem e mulher nas questões de promoção e defesa da vida.

\section{Referências Bibliográficas}

BRASIL, Ministério da Saúde. Atenção Humanizada ao Abortamento: norma técnica. Brasília: Ministério da Saúde, 2005.

CELAM. Documento de Aparecida (DAp). São Paulo: CNBB / Paulinas / Paulus, 2007.

CNBB. Diretório da Pastoral Familiar (DPF): São Paulo: CNBB/ Paulinas, $7^{\mathrm{a}}$ ed. 2011.

DIDAKÉ: O catecismo dos primeiros cristãos para as comunidades de hoje. São Paulo: Paulinas. 2007.

HARING, Bernard. "A theological evaluation". In: NOONAN JR. John Thomas. The morality of abortion: legal and historical perspectives. Harvard University Press / Cambridge, Massachusetts, 1970, p.123-145.

JOÃO PAULO II, Cartas às Mulheres, São Paulo: Paulinas, 1995.

JOÃO PAULO II, Evangelium Vitae, Carta Encíclica - Sobre o valor e a inviolabilidade da vida humana. São Paulo: Paulinas, 1995.

NOONAN JR. John Thomas. The morality of abortion: legal and historical perspectives. Harvard University Press/Cambridge, Massachusetts, 1970.

PAPA PAULO VI. Humanae Vitae. (1968) Carta Encíclica sobre a Regulação da Natalidade. Disponível em: http://www.vatican.va/holy_father/ paul_vi/encyclicals/documents/hf_p-vi_enc_25071968_humanae-vitae_ po.html. Acessado em 15/02/2014.

SANCHES, M.A. "O Aborto numa Perspectiva Pastoral”. REB - Revista Eclesiástica Brasileira, Fasc. 285, Janeiro, 2012, p.119s.

SANDI, Stella de Faro e BRAZ, Marlene. "As mulheres brasileiras e o aborto: uma abordagem bioética na saúde pública". Revista Bioética, 2010; vol. 18 n.1, Brasília: CFM, p.131 -153. 
VATICANO II, Gaudium et Spes (1965). Disponível em: http://www. vatican.va/archive/ hist_councils/ii_vatican_council/documents/vat-ii const_19651207_gaudium-et-spes_po.html. Acessado em 15/02/2014.

Mário Antônio Sanches

Doutor em Teologia pela EST/IEPG - RS

Professor titular da PUCPR onde coordena o Mestrado de Bioética

Curitiba/PR - Brasil

E-mail: m.sanches@pucpr.br

Castorina H. V. Casagrande

Bacharel em Teologia pela PUCPR

Bolsista de iniciação científica CNPq de 2010-2012

Curitiba/PR - Brasil

E-mail: castorina_vidal@hotmail.com

Eva Maria Duarte Gomes

Bacharel em Teologia pela PUCPR

Bolsista iniciação científica PUCPR de 2011-2012

Curitiba/PR - Brasil

E-mail: evaduarteg@hotmail.com

Recebido em: 15/02/14

Aprovado em: 26/05/14 